UDK: 711.4:911.375.6:551.583

DOI: 10.5379/urbani-izziv-2015-26-02-000

Boštjan KERBLER

\title{
Urbani prostor postsocialističnih mest, neformalnih naselij in degradiranih območij $v$ času podnebnih sprememb
}

V tokratni številki revije Urbani izziv je mestni prostor predstavljen prek alternativnih prihodnosti urbanih pokrajin, omrežij javnih prometnih sistemov, aspiracij stanovalcev neformalnih urbanih naselij in prenove degradiranih območij. Objavljeni prispevki nadgrajujejo nekatera spoznanja avtorjev, ki so svoje ugotovitve objavili $v$ predhodnih številkah naše revije. $V$ ta namen smo opravili kritično primerjalno analizo med temi prispevki, ki vam jo predstavljamo v nadaljevanju. $S$ tem smo želeli objavam v naši reviji in znanstvenim dognanjem, ki so bila v njih predstavljena, dati dodatno vrednost in jim še povečati znanstveno kakovost.

\section{Alternativne prihodnosti urbanih pokrajin v obdobju podnebnih sprememb}

Amin Rastandeh (2015) se v prispevku Izzivi in potenciali uporabe alternativnih prihodnosti pokrajin v obdobju podnebnih sprememb: pregled literature in raziskava osredotoča na možnost uporabe analize alternativnih prihodnosti in scenarijev pri krajinskem načrtovanju v času podnebnih sprememb, kar bi zagotovilo širši pogled in poglobljeno razumevanje tega pristopa ter $s$ tem njegovo boljšo in učinkovitejšo uporabo v prihodnosti. Pri tem avtor izhaja iz spoznanja, da zaradi družbenogospodarske privlačnosti mest vse več svetovnega prebivalstva živi v urbanih okoljih. Iz enakih domnev izhajajo že avtorji člankov, ki so bili objavljeni v tej reviji leta 2012, in sicer Arun Kumar Acharya in Manuel R. Barragán Codina v članku Družbena segregacija avtohtonih migrantov v Mehiki: primer mesta Monterrey, Juyong Zhang idr. v članku Življenje v spreminjajoči se kitajski urbani pokrajini: študija mesta Dalian in Chen Gou v članku State rescaling, contested space, and inequality in the globalizing city-regions of China: Conceptual issues and empirical evidence. Acharya in Barragán Codina sta pri analizi družbene segregacije avtohtonih migrantov izhajala iz pojava, ki je značilen za severno Mehiko. Gre za nenadzorovano ruralno urbano migracijo oziroma preseljevanje ljudi s podeželja v mesta. Zhang idr. opisujejo rast Daliana, drugega najpomembnejšega mesta na jugu province Liaoning na severovzhodu Kitajske. Avtorji ugotavljajo, da je do največjih sprememb prišlo po letu 1984, ko so mesto razglasili za posebno gospodarsko območje, zlasti pa v 90. letih 20. stoletja, ko je postal župan Bo Xilai, ki je v mestu uredil parke, avtoceste in krožišča. Ugotovili so, da je s prostorskim širjenjem mesta tradicionalno grajeno okolje skoraj izginilo in da je Dalian postal sodobno mesto, $v$ katerem se gradijo velika stanovanjska naselja za priseljence. Tudi Gou se osredotoča na rast mest in mestnega prebivalstva na Kitajskem, in sicer v Pekingu, Šanghaju in Guangzhou. Na podlagi tega ugotavlja, ali ustvarja ta pojav segmentacijo, premik oziroma polarizacijo območij, namenjenih bivanju na eni in proizvodnji na drugi strani.

Rastandeh (2015) meni, da je posledica take urbanizacije tudi nenačrtno širjenje mest in izčrpavanje naravnih virov po svetu, o čemer so v tej reviji leta 2012 pisali 
tudi Michael W. Mehaffy in Tigran Haas v članku Poststrukturalisti križem rok opazujejo svet v plamenih: izhod iz samoustvarjene krize »arhitekturne kulture in Franklin Obeng-Odoom v članku Politično-ekonomski temelji novega zahodnoafriskega naftnega mesta Sekondi-Takoradi. Mehaffy in Haas sta se osredotočila na ameriška mesta in njihova predmestja in opozorila, da se vzorci netrajnostnega urbanega razvoja in rasti vse bolj krepijo ter da se ta ameriški praksa vse bolj širi in izvaža po vsem svetu. Njuno ugotovitev pritrjuje Obeng-Odoom za zahodnoafriško mesto Sekondi-Takoradi, v katerem so leta 2007 odkrili nafto. Zaradi hitre urbanizacije in demografske rasti je to mesto postalo eno najhitreje rastočih mest na črni celini, $s$ čimer se je pridružilo drugim hitro rastočim mestom in urbaniziranim območjem s podobnimi nahajališč virov v Afriki, kot so Copperbelt v Zambiji, Kano v Nigeriji, Gaborone v Bocvani in Kataroo v Tanzaniji.

Rastandeh (2015) ugotavlja, da so raziskovalci v skladu s temi razvojnimi smernicami začeli intenzivneje preučevati tudi vplive podnebnih sprememb na urbanizirana območja. Po njegovem mnenju bi lahko podnebne spremembe kot eden najmočnejših povzročiteljev sprememb rabe in pokrovnosti tal pripeljale do močnih pretresov $\mathrm{v}$ urbaniziranih pokrajinah. Prepričan je, da zato $v$ času hitre urbanizacije in podnebnih sprememb zamišljanje sprememb v pokrajini, ki so posledica urbanizacije in podnebnih sprememb, zagotavlja osnovo za informirane odločitve pri sprejemanju ustrezne krajinske politike. Prikaz verjetnih učinkov teh politik na prihodnost pokrajine je lahko namreč sestavni del blažilnih in prilagoditvenih strategij pri načrtovanju urbaniziranih pokrajin. Kot odziv na urbane izzive, ki jih povzročajo podnebne spremembe, avtor predlaga, naj se analiza alternativnih prihodnosti in scenarijev uporabi kot učinkovito orodje, ki bi omogočalo sprejemanje informiranih odločitev glede politike rabe in pokrovnosti tal in seznanjanje o tem, kaj nam lahko prinese prihodnost. Avtor obravnava dve glavni vprašanji, in sicer ali je analiza alternativnih prihodnosti in scenarijev ustrezno in zanesljivo orodje za prikazovanje prihodnjih pokrajin in $s$ tem za sprejemanje politike krajinskega načrtovanja $\mathrm{v}$ času podnebnih sprememb ter kakšne so trenutne težave in potenciali, povezani z uporabo tega odločitvenega orodja v resničnem svetu.

\section{Omrežja javnih prometnih sistemov v postsocialističnih mestih}

Lucian-Ionuț Roșu in Alexandra Blăgeanu (2015) v članku Ocena težav in uspešnosti javnega prometnega omrežja v postkomunisticnem mestu $z$ uporabo kvantitativnega prostorskega pristopa izhajata iz spoznanj, da je dinamika mest v Vzhodni Evropi po padcu komunizma (kot posledica sprememb, ki jih je povzročil prehod k novi ideologiji) razkrila številne pomanjkljivosti lokalnih javnih storitev. Do podobnih spoznanj so prišli Sasha Tsenkova v članku Preplet stanovanjskih politik in odzivi ljudi na stanovanjske probleme v postsocialističnih mestih, ki je bil objavljen v reviji Urbani izziv leta 2014, ter Janez Koželj in Jasna Stefanovska v članku z naslovom Urbanistično načrtovanje in težave tranzicijkega razvoja v Skopju iz leta 2012. Sasha Tsenkova se je v članku osredotočila na prizadevanja za oblikovanje tržnega stanovanjskega sistema in konkurenčnih stanovanjskih trgov v postsocialističnem urbanem okolju. Po njenih ugotovitvah so namreč spremembe na stanovanjskem področju v postsocialističnih mestih povečale razlike v stanovanjskih razmerah, kar je povzročilo velike ovire v cenovni dostopnosti stanovanj, propadanje privatiziranih stanovanj in pojav slumov. Prav cenovna dostopnost stanovanj (poleg rastoče revščine, neformalnosti in izključenosti) naj bi bila po mnenju avtorice najbolj pereča težava postsocialističnih držav. Koželj in Stefanovska opozarjata na še eno težavo v teh državah, in sicer na 
urbanistično načrtovanje. Avtorja sta se pri tem osredotočila na makedonsko glavno mesto, ki je po njunem mnenju tako kot številna druga mesta v sosednjih državah doživelo radikalne spremembe, ki so v zadnjih dvajsetih letih in že prej vplivale na urbanistične procese. Kriza, ki je v času tranzicije zajela Skopje, naj bi povzročila slabšo kakovost grajenega okolja in ustvarila plodna tla za špekulativno gradnjo. Avtorja sta prepričana, da prav zaradi tega urbanistično načrtovanje ne more več delovati kot orodje nadzora in razvoja, katerega glavni cilj je varovati in spodbujati javne interese. Težave preobrazbe urbane pokrajine med prehodom iz komunizma v kapitalizem obravnavata tudi Lazaros E. Mavromatidis in Asimina Mavromatidi v članku Ponovno odkritje dvoma o ikoni: studija izmišljenega primera iz prestolnice nekdanje sovjetske države iz leta 2012, ki se osredotoča na armensko prestolnico Erevan. Po mnenju avtorjev je z izbiro Erevana kot območja raziskave, upoštevanjem sovjetskega obdobja te prestolnice in osredotočanjem na njeno postsovjetsko obdobje v članku prikazano, da je bila prostorska proizvodnja usmerjena v organizacijo družbenega življenja, da bi z uradnim in neuradnim državnim načrtovanjem služila prevladujočim interesom posameznega zgodovinskega obdobja. Avtorja poudarjata, da lahko prehod iz sovjetskega v liberalni kapitalistični sistem vpliva na kulturno pokrajino mesta $\mathrm{z}$ oblikovanjem »navideznih pokrajinskih « podob, da bi imelo mesto v sodobnem kontekstu globalizacije pozitivno podobo.

Roşu in Blăgeanu (2015) pa opozarjata na še eno veliko težavo, s katero se soočajo vzhodnoevropska mesta, in sicer na težave javnega prometnega sistema. Pri tem poudarjata, da se s podobnimi težavami, ki jih povzroča slaba prilagodljivost hitrim spremembam v urbanem okolju, ki so posledica postkomunistične tranzicije, spopadajo pravzaprav vsi javni mestni prometni sistemi v Vzhodni Evropi. Za določitev in ponazoritev pomanjkljivosti tega sistema na obravnavanem območju sta analizirala prometno omrežje v romunskem mestu Iasi, pri čemer sta upoštevala različne vidike njegove učinkovitosti. Opozorila sta, da bi bilo treba pri ocenjevanju kakovosti javnega prometnega sistema izhajati tudi iz mnenj uporabnikov (v njunem primeru potnikov) o različnih lastnostih (pogostnosti, ceni, lastnostih vozil, času potovanja itd.), ki oblikujejo splošno predstavo o kakovosti zagotovljenih storitev. Podoben pristop so uporabili Špela Verovšek idr. v članku Vidni jezik za predstavitev interdisciplinarnih usebin na področju urbanega razvoja: izbrani izsledki študije, ki je bil leta 2013 objavljen v tej reviji. Prepričani so, da se s soočanjem in integracijo mnenj ter interdisciplinarnim pristopom $\mathrm{k}$ prostorskim problemom odpira težavno področje usklajevanja mnenj oziroma predlogov stroke, interesnih skupin iz gospodarstva, širše javnosti in akterjev oblasti. Po njihovem mnenju ima dihotomija med strokovno javnostjo in laiki različne vzroke. Del težav naj bi izhajal iz različnih interesov in vrednotnih prioritet, ki sicer močno variirajo tudi znotraj posameznih skupin splošne laične javnosti, velik del nesoglasij pa je posledica motenj v sporazumevanju, o čemer je leta 2012 (med drugim) pisal že Igor Bizjak v članku Izboljšanje javne participacije pri prostorskem načrtovanju s pomočjo orodij spleta 2.0. Njegovo razmišljanje je potrdil tudi Aidan Cerar v članku z naslovom Od odziva do pobude: potencial kontributivne participacije, ki je bil v Urbanem izzivu objavljen leta 2014.

Raziskava Roșuja in Blăgeanuja (2015) naj bi bila reprezentativna, zato naj bi bil model, ki je bil razvit v tej raziskavi in razkriva zmožnost postkomunističnega sistema, da se prilagodi urbanim spremembam, uporaben za katero koli vzhodnoevropsko mesto. Ker pa izsledki raziskave potrjujejo neskladje med javnim prometnim omrežjem in rastočimi potrebami mestnih prebivalcev, so po njunem mnenju uporabni za lokalne oblikovalce politike in različne déležnike, na primer vlagatelje, nevladne organizacije, gospodarstvenike in načrtovalce urbanega prostora. V zvezi s slednjimi 
so že leta 2012 Visar Hoxha idr. v članku Kulturni dejavniki, ki vplivajo na urbanistov namen urejanja javnih prostorov $v$ Prištini poudarili, da naj bi urbanistove predstave poleg abstraktnejših zamisli obsegale tudi načrtovalske prakse konkretnejše urbane infrastrukture, med katere spada tudi prometni sistem mesta. Da je dostopnost eden ključnih elementov kakovosti urbanega okolja za prebivalce in druge uporabnike, opozarjata tudi Alenka Temeljotov Salaj in Andrej Pompe v članku z naslovom Primerjalna analiza kvalitativnih kriterijev urbanizma in tržne znamke, ki je bil $\mathrm{v}$ naši reviji objavljen leta 2014.

\section{Preference in aspiracije stanovalcev neformalnih urbanih naselij}

V članku Stanovanjske aspiracije v neformalnem urbanem naselju: študija primera avtorji Akunnaya P. Opoko idr. (2015) ugotavljajo, da imajo prebivalci Nigerije, zlasti prebivalci neformalnih naselij, v zadnjem času izjemno velike aspiracije po lastniškem stanovanju ali hiši. Gospodinjstva z nizkimi dohodki se zato pogosto usmerijo na neformalni stanovanjski trg, ki ga je Ashley Gunter v članku Renting shacks: Landlords and tenants in the informal housing sector in Johannesburg South Africa, ki je bil objavljen leta $2014 \mathrm{v}$ posebni izdaji te revije, opisala kot klasični neoliberalni trg, na katerem je stanovanjska ponudba slaba in povpraševanje stalno visoko. Po njenem mnenju sta namreč v državah na tako imenovanem »globalnem jugu « vse večji primanjkljaj stanovanj in nezadosten fond poceni stanovanj na formalnem stanovanjskem trgu, ki ne more zadovoljiti povpraševanja, povzročila širjenje neformalnih naselij in bivališč ter širjenje neformalnega stanovanjskega trga. Avtorica je prepričana, da je prav zato $\mathrm{v}$ številnih mestih na globalnem jugu stanovanjski trg neformalen. V zvezi s tem so Lochner Marais idr. v članku From informality to formality to informality: Extralegal land transfers in an upgraded informal settlement of South Africa, ki je bil objavljen v posebni izdaji te revije leta 2014, opozorili, da so $\mathrm{v}$ veliko primerih procesi preoblikovanja trga iz neformalnega $\mathrm{v}$ formalnega prek formalizacije lastninskih pravic povzročili samo še več novih neformalnih oblik. Neformalni sektor naj bi zato postal glavni vir preživetja družin in skupnosti v mestih na globalnem jugu, do česar je bila še posebej kritična Sophie Oldfield v članku Intertwining lives and logics: Household and informal economies in Cape Town, objavljenem v posebni izdaji naše revije leta 2014. Opozorila je, da je neformalno gospodarstvo lokalnega značaja, ima omejene povezave s formalnim gospodarstvom in temelji na preživitvenih praksah, ki veljajo za zelo nekonkurenčne.

Zaradi opisanega izhajajo Opoko idr. (2015) v svojem članku izhajajo iz domneve, da je ustrezno razumevanje stanovanjskih aspiracij in preferenc bistveno za doseganje učinkovitega urbanega stanovanjskega trga, ki zadovoljuje pričakovanja in aspiracije vseh kategorij gospodinjstev v neformalnih mestnih naseljih v Nigeriji. Preučili so stanovanjske aspiracije gospodinjstev v neformalnem naselju Ayobo v predmestju Lagosa, v katerem je veliko gospodinjstev z nizkimi dohodki. Glavni cilji njihove raziskave so bili preučiti lastnosti stanovanj, stanovanjsko preteklost in aspiracije prebivalcev ter ugotoviti, kateri dejavniki vplivajo na stanovanjske aspiracije prebivalcev Ayoba. Prav v zvezi z aspiracijami se avtorji sklicujejo na članek, Socialna

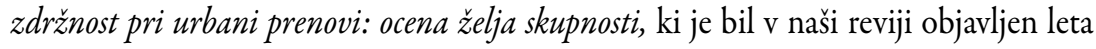
2012. Daniel Chi Wing Ho idr. v njem aspiracijo opisujejo kot posameznikov odnos do kraja, stvari ali procesa, in dodajajo, da posameznikove stanovanjske aspiracije določajo, kako bo ta ukrepal v svojem grajenem okolju v zvezi s sanacijo ali obnovo. Opoko idr. (2015) omenjajo tudi članek Clintona Aigbavboa in Wellingtona Thwala $\mathrm{z}$ naslovom Structural equation modelling of building quality constructs as a predictor of satisfaction in subsidised low-income housing, ki je bil objavljen v posebni izdaji 
naše revije leta 2014. Raziskava, ki je bila predstavljena $\mathrm{v}$ tem članku, je namreč razkrila različne ravni zadovoljstva z obstoječimi stanovanji ter veliko neskladje med trenutnimi stanovanjskimi razmerami in aspiracijami ljudi v Južnoafriški republiki, kar so Opoko idr. (2015) ugotovili tudi za svoje preučevano območje v Nigeriji. Obe raziskavi sta tudi pokazali, da je to, v kolikšni meri so stanovalci zadovoljni $s$ stanovanjem, merilo, ki pokaže ujemanje med njihovimi stanovanjskimi izkušnjami, preferencami in aspiracijami. Opoko idr. (2015) so prepričani, da njihova raziskava ponuja nov vpogled $\mathrm{v}$ stanovanjske aspiracije prebivalcev neformalnega naselja $\mathrm{v}$ enem najhitreje rastočih svetovnih velemest, $s$ čimer prispeva $k$ trenutno pomembnemu diskurzu o stanovanjih v neformalnih urbanih naseljih v državah v razvoju, kjer neformalna stanovanja ostajajo velika težava za trajnostno rast mest in njihov razvoj.

\section{Prenova degradiranih območij in ukrepi za trajnostni razvoj}

Mohammed Nawrose Fatemi in Tahmina Rahman (2015) v članku z naslovom Prenova degradiranega območja Hazaribagh: nujni ukrep za trajnostni razvoj Dake izhajata iz enakih spoznanj kot Rastandeh (2015), in sicer da se urbana območja širijo in da vse več svetovnega prebivalstva živi v mestih. Ugotavljata, da tako zgoščanje prebivalstva močno obremenjuje infrastrukturo in objekte $\mathrm{v}$ velikih mestih, na kar so opozorili že avtorji drugih treh člankov, ki so bili objavljeni v reviji Urbani izziv. Prvi članek z naslovom Land Administration System structured land rent residuals and China's urban sprawl - A case study of Dashi, Guangzhou je bil objavljen v posebni izdaji revije leta 2012, napisala pa sta ga Liu Xuan in Li Xun. Drugi članek z naslovom Preskrba stanovanji v dolini Katmanduja: javne in zasebne pobude je bil objavljen leta 2010, napisal pa ga je Bijaya K. Shrestha, ki ugotavlja, je nenačrtna rast naselij v dolini Katmanduja posledica hitre urbanizacije, naraščajoče revščine, visokih stroškov zemljišč ter gradnje in odvisnosti od tradicionalne prakse lastniško zgrajenih stanovanj. Ta rast naj bi povzročala ogromen stanovanjski primanjkljaj in slabe bivalne razmere. Isti avtor v članku z naslovom Stanovanjske soseske v Katmanduju: glavne oblikovalske smernice za preučevane soseske v prestolnici Nepala navaja, da imajo njihovi prebivalci v vsakdanjem življenju težave z nezadostno vodno oskrbo, slabo kanalizacijo ter slabo vzdrževanimi ulicami in javnimi prostori. Vse to po njegovem prispeva k oslabljenemu občutku pripadnosti kraju in skupnosti. Ta članek je bil objavljen v reviji leta 2013.

Fatemi in Rahman (2015) potrjujeta to misel, ko poudarjata, da se $s$ tovrstnimi težavami sooča veliko mest po svetu, menita pa tudi, da imajo težave z velikim številom nerabljenih površin na privlačnih zemljiščih, ki pa okolju niso prijazna in so pogosto močno onesnažena. To naj bi bilo značilno tudi za glavno bangladeško mesto Daka, ki je enajsto največje velemesto na svetu. Kot pišeta avtorja, je nastalo in se razširilo na bregovih reke Burigange, na katerih so se v značilnem vzorcu razvile tudi najpomembnejše industrijske panoge v mestu. Med njimi je ena najstarejših usnjarska industrija (med domačini znana kot strojarstvo). Največ strojarn naj bi bilo v mestnem predelu Hazaribagh, ki je z $90 \%$ vseh obratov vodilno usnjarsko območje $\mathrm{v}$ državi, zato je v članku preučeno kot študija primera. Vendar pa so, kot navajata avtorja, uporaba tehnologije slabše kakovosti, neustrezno ravnanje z industrijskimi odpadki in pomanjkanje naprav za obdelavo odpadkov uničili ekologijo tega območja ter močno obremenili cestno omrežje in grajeno infrastrukturo v okolici. Podobno se je zgodilo tudi v mestu Solapur v indijski državi Maharaštra, le da je tam bila glavni vir onesnaženja in degradacije urbanih površin tekstilna industrija. $\mathrm{O}$ tem so v Urbanem izzivu pisali Rahul B. Hiremath idr., in sicer v članku z naslovom Celostni pristop mreženja za trajnostno tekstilno panogo v indijskem mestu Solapur, 
ki je bil objavljen leta 2012. Solapur opisujejo kot hitro rastoče mesto, ki je najbolj znano po tekstilnih izdelkih, kot so brisače, posteljnina in bombažne odeje. $V$ mestu naj bi delovalo približno 25.000 obratov z mehaničnimi statvami, ki zaposlujejo približno 100.000 delavcev. Množična proizvodnja tekstila v Solapuru temelji na proizvodnem procesu in kemikalijah, pri čemer se porabi ogromna količina vode in elektrike, kar močno obremenjuje okolje. Tudi čistilne naprave za odpadne vode naj bi bile slabo urejene in posledica tega je veliko industrijsko onesnaženje. Avtorji so zato ocenili uporabljene modele in metode ter izmerili vpliv tekstilne industrije na okolje, zdravje in biotsko raznovrstnost v Solapuru. Na podlagi teh izsledkov so predlagali trajnostni celostni model blaženja okolijskih tveganj v mestu.

Tudi Fatemi in Rahman (2015) v članku predlagata rešitev za zmanjšanje obremenitve okolja in priložnost za trajnostno mestno prenovo. Rešitev naj bi temeljila na selitvi strojarn iz Hazaribagha in njegovi sanaciji. V raziskavi zato preučujeta potencial območja Hazaribagh, da kot primer načrtovanega trajnostnega območja, ki ga ne zaznamuje močna onesnaženost, po kateri ta lokacija trenutno slovi, postane zgled vsej državi. Po njunem mnenju lahko prenova tega degradiranega območja služi tudi kot model trajnostnih sosesk 21. stoletja, ki vključujejo vse sodobne objekte in okolju prijazne sestavine, potrebne za zdravo bivanje.

Boštjan Kerbler, urednik

Urbanistični inštitut Republike Slovenija, Ljubljana, Slovenija

E-pošta: bostjan.kerbler@uirs.si

\section{Viri in literatura}

Acharya, A. K., in Barragán Codina, M. R. (2012): Družbena segregacija avtohtonih migrantov v Mehiki: primer mesta Monterrey. Urbani izziv, 23(1), str. 64-73.

DOI: 10.5379/urbani-izziv-2012-23-01-006

Aigbavboa, C., in Thwala, W. (2014): Structural equation modelling of building quality constructs as a predictor of satisfaction in subsidised low-income housing. Urbani izziv, 25(supplement), str. 134-147. DOI: 10.5379/urbani-izziv-en-2014-25-supplement-010

Bizjak, I. (2012): Izboljšanje javne participacije pri prostorskem načrtovanju s pomočjo orodij spleta 2.0. Urbani izziv, 23(1), str. 36-48. DOI: 10.5379/urbani-izziv-2012-23-01-004

Cerar, A. (2014): Od odziva do pobude: potencial kontributivne participacije. Urbani izziv, 25(1), str. 24-36. DOI: 10.5379/urbani-izziv-2014-25-01-002

Cheng, G. (2012): State rescaling, contested space, and inequality in the globalizing city-regions of China: Conceptual issues and empirical evidence. Urbani izziv, 23(supplement 2), str. S137S149. DOI: 10.5379/urbani-izziv-2012-23-supplement-2-012

Fatemi, M. N., in Rahman, T. (2015): Prenova degradiranega območja Hazaribagh: nujni ukrep za trajnostni razvoj Dake. Urbani izziv, 26(2), str. 60-73. DOI: 10.5379/urbani-izziv-2015-26-02-004

Gunter, A. (2014): Renting shacks: Landlords and tenants in the informal housing sector in Johannesburg South Africa. Urbani izziv, 25(supplement), str. 96-107.

DOI: 10.5379/urbani-izziv-en-2014-25-supplement-007

Hiremath, R. B., Kattumuri, R., Kumar, B., Khatri, V. N., in Patil, S. S. (2012): Celostni pristop mreženja za trajnostno tekstilno panogo v indijskem mestu Solapur. Urbani izziv, 23(2), str. 64-74. DOI: 10.5379/urbani-izziv-2012-23-02-007

Ho, D. C. W., Yau, Y., Law, C. K., Poon, S. W., Yip, H. K., in Liusman, E. (2012): Socialna zdržnost pri urbani prenovi: ocena želja skupnosti. Urbani izziv, 23(1), str. 49-63.

DOI: 10.5379/urbani-izziv-2012-23-01-005

Hoxha, V., Dimitrovska Andrews, K., in Temeljotov Salaj, A. (2014): Kulturni dejavniki, ki vplivajo na urbanistov namen urejanja javnih prostorov v Prištini. Urbani izziv, 25(2), str. 5-28. DOI: 10.5379/urbani-izziv-2014-25-02-001

Marais, L., Ntema, J., Cloete, J., in Venter, A. (2014): From informality to formality to informality: Extralegal land transfers in an upgraded informal settlement of South Africa. Urbani izziv, 25(su- 
pplement), str. S148-S161. DOI: 10.5379/urbani-izziv-en-2014-25-supplement-011

Mavromatidis, L. E., in Mavromatidi, A. (2012): Ponovno odkritje dvoma o ikoni: študija izmišljenega primera iz prestolnice nekdanje sovjetske države. Urbani izziv, 23(2), str. 5-17. DOI: 10.5379/urbani-izziv-2012-23-02-001

Mehaffy, M. W., in Haas, T. (2012): Poststrukturalisti križem rok opazujejo svet v plamenih: izhod iz samoustvarjene krize »arhitekturne kulture«. Urbani izziv, 23(1), str. 5-12. DOI: 10.5379/urbani-izziv-2012-23-01-001

Obeng-Odoom, F. (2012): Politično-ekonomski temelji novega zahodnoafriškega naftnega mesta Sekondi-Takoradi. Urbani izziv, 23(2), str. 45-54. DOI: 10.5379/urbani-izziv-2012-23-02-005

Oldfield, S. (2014): Intertwining lives and logics: Household and informal economies in Cape Town. Urbani izziv, 25(supplement), pp. S36-S46.

DOI: 10.5379/urbani-izziv-en-2014-25-supplement-003

Opoko, A. P., Ibem, E. O., in Adeyemi, E. A. (2015): Stanovanjske aspiracije v neformalnem urbanem naselju: študija primera. Urbani izziv, 26(2), str. 45-59.

DOI: 10.5379/urbani-izziv-2015-26-02-003

Pompe, A., in Temeljotov Salaj, A. (2014): Primerjalna analiza kvalitativnih kriterijev urbanizma in tržne znamke. Urbani izziv, 25(1), str. 5-23. 10.5379/urbani-izziv-2014-25-01-001

Rastandeh, A. (2015): Izzivi in potenciali uporabe alternativnih prihodnosti pokrajin v obdobju podnebnih sprememb: pregled literature in raziskava. Urbani izziv, 26(2), str. 11-30. DOI: 10.5379/urbani-izziv-2015-26-02-001

Roșu, L-I., in Blăgeanu, A. (2015) Ocena težav in uspešnosti javnega prometnega omrežja v postkomunističnem mestu z uporabo kvantitativnega prostorskega pristopa. Urbani izziv, 26(2), str. 31-44. DOI: 10.5379/urbani-izziv-2015-26-02-002

Shrestha, B. K. (2010): Preskrba s stanovanji v dolini Katmanduja: javne in zasebne pobude. Urbani izziv, 21(2), str. 16-26. DOI: 10.5379/urbani-izziv-2010-21-02-002

Shrestha, B. K. (2013): Stanovanjske soseske v Katmanduju: glavne oblikovalske smernice. Urbani izziv, 24(1), str. 39-57. DOI: 10.5379/urbani-izziv-2013-24-01-003

Stefanovska, J., in Koželj, J. (2012): Urbanistično načrtovanje in težave tranzicijskega razvoja v Skopju. Urbani izziv, 23(1), str. 16-24. DOI: 10.5379/urbani-izziv-2012-23-01-002

Tsenkova, S. (2014): Preplet stanovanjskih politik in odzivi ljudi na stanovanjske probleme v postsocialističnih mestih. Urbani izziv, 25(2), str. 19-35. 10.5379/urbani-izziv-2014-25-02-002

Verovšek, S., Juvančič, M., in Zupančič, T. (2013): Vidni jezik za predstavitev interdisciplinarnih vsebin na področju urbanega razvoja: izbrani izsledki študije. Urbani izziv, 24(2), str. 65-77. DOI: 10.5379/urbani-izziv-2013-24-02-006

Xuan, L., in Xun, L. (2012): Land Administration System structured land rent residuals and China's urban sprawl - A case study of Dashi, Guangzhou. Urbani izziv, 23(supplement 2), str. S150-S160. DOI: 10.5379/urbani-izziv-en-2012-23-supplement-2-013

Zhang, J., Kotze, N., in Yu, M. (2012): Življenje v spreminjajoči se kitajski urbani pokrajini: študija mesta Dalian. Urbani izziv, 23(2), str. 18-26. DOI: 10.5379/urbani-izziv-2012-23-02-002 